\title{
Acute Effect of Chest Physical Therapy on Arterial Blood Gases for Mechanical Ventilated Patients
}

\author{
HEBA A. ABDEEN, Ph.D.*; SAAD M. ELGENDY, M.Sc.*; NAGY L. NASSEF, Ph.D.* and \\ YOUSSEF M.A. SOLIMAN, M.D.** \\ The Department of Physical Therapy for Cardiovascular/Respiratory Disorder and Geriatrics, Faculty of Physical Therapy, \\ Cairo University* and The Department of Chest Diseases, Faculty of Medicine, Cairo University**
}

\begin{abstract}
Background: Patients receiving mechanical ventilation have an increased risk of complications resulting in excess morbidity and mortality.

Aim of Study: This study aimed to identify the acute effect of chest physical therapy on arterial blood gases of mechanically ventilated patients.

Material and Methods: Sixty mechanically ventilated patients participated in the study. Their age ranged from 40 to 60 years. The patients were assigned into one study group including both sexes who received a chest physiotherapy protocol in form of (manual hyperinflation, vibration, percussion, suctioning, upper and lower limbs exercise and ending position) for one session. Arterial Blood Gases (ABG) including $\left(\mathrm{pH}, \mathrm{PaO}_{2}, \mathrm{SO}_{2}, \mathrm{PaCO} 2\right.$ and $\left.\mathrm{HCO} 3\right)$ were assessed by arterial blood sample analysis through the Laboratory GEM premier 3000 device. All the assessment was done for every patient pre and post chest physiotherapy protocol.
\end{abstract}

Results: The results revealed a marked improvement in arterial blood gas exchange as compared to base line reflected by a highly significant statistical increase in $\mathrm{PaO}_{2}$ and $\mathrm{SaO}_{2}$ $(p<0.001)$ and a significant decrease in $\mathrm{PaCO}_{2}(p<0.001)$ while with no significant changes regarding $\mathrm{pH}$ and $\mathrm{HCO} 3$ ( $p=0.36$ and 0.15 respectively).

Conclusion: Chest physiotherapy protocol is an effective method for improving arterial blood gases of mechanical ventilated patients acutely.

Key Words: Chest physical therapy - Arterial blood gases $(A B G)$ - Mechanical ventilation.

\section{Introduction}

AN Intensive Care Unit (ICU) is a specially staffed and equipped, separate and self-contained area of a hospital dedicated to the management and monitoring of patients with life threatening conditions. It provides special expertise and the facilities for

Correspondence to: Dr. Saad M. Elgendy, E-Mail: Saad 01015553230@yahoo.com. the support of vital functions and uses the skills of medical, nursing and other personnel experienced in the management of these problems [1].

Mechanical ventilation is the technique through which gas is moved toward and from the lungs through an external device connected directly to the patient. The clinical objectives of mechanical ventilation can be highly diverse: To maintain gas exchange, to reduce or substitute respiratory effort, to diminish the consumption of systemic and/or myocardiac $\mathrm{O}_{2}$, to obtain lung expansion, to allow sedation, anesthesia and muscle relaxation, and to stabilize the thoracic wall, etc [2]

The need for mechanical ventilation is a common feature of the patient requiring admission to the ICU. Indeed, the expansion and increased sophistication of the mechanical ventilator parallels similar developments in the respiratory therapy profession [3]. Mechanical ventilation is always a lifesaving intervention, but carries many potential complications including pneumothorax, lung injury, alveolar damage, and ventilator-associated pneumonia [4].

Arterial Blood Gas (ABG) analysis is an essential part of diagnosing and managing a patient's oxygenation status and acid-base balance. The usefulness of this diagnostic tool is dependent on being able to correctly interpret the results [5]

Physiotherapy has proved to be an important component in the management of patients in ICU and has shown short-term and medium-term benefits. Chest physiotherapy results in physiological changes, such as significant alterations in hemodynamic, respiratory, and intracranial parameters [6]. 
Chest physiotherapy routinely treat most of the ICU patients with various chest physiotherapy techniques such as manual hyperinflation, suctioning, patient positioning, chest vibrations, chest percussions, various coughing techniques in combination or individually to prevent pulmonary complications in the ICU [7].

Manual Hyperinflation (MH), which involves lung ventilation using a manual resuscitation bag, is a technique used in mechanically ventilated patients to assist with clearance of pulmonary secretions in addition to endotracheal suction [8]

Percussion and vibration and shaking methods are based on the assumption that applying an external force to the chest wall to loosen the mucus facilitates airway mobilization and clearance, it involves rhythmical beating with properly shaped hands on the chest wall over specific regions of the lungs and removing the mucus [9].

Patient positioning in ICU is important to break through the routine monotonic delivery of mechanical ventilation and to favor the clearance of respiratory secretions, the prevention of pressure sores and ventilator acquired pneumonia, and the improvement in lung volume and oxygenation [10]

Mobilization refers to physical activity sufficient to elicit acute physiological effects that improve ventilation, central and peripheral perfusion, circulation, muscle metabolism and alertness and countermeasures for venous stasis and deep vein thrombosis [11]. Early mobilization in the ICU has a significant impact on patients' functional outcomes [12].

\section{Patients and Methods}

The current study was conducted in the ICUs of Cairo University Hospitals in the period from August 2019 to March 2020 to identify the acute effect of chest physical therapy on arterial blood gases of mechanically ventilated patients.

\section{1- Patients:}

Sixty mechanically ventilated patients (males= 33 and females=27) participated in this study. The patients were recruited from the ICUs of Cairo University Hospitals in the period from August 2019 to March 2020. Their age ranged from 40 to 50 years.

They were all assigned into one study group. They received a chest physiotherapy protocol in form of (manual hyperinflation, vibration, percussion, suctioning, upper and lower limbs exercise and ending position) for one session.

\section{Inclusion criteria:}

Sixty patients from ICUs of Cairo University Hospitals. They were on invasive mechanical ventilator. Their age ranged from 40-60 years old.

\section{Exclusion criteria:}

The patients with one or more of the following criteria were excluded: Haemo-dynamic instability, patients on non invasive mechanical ventilator, acute pulmonary edema, untreated pneumothorax, open heart surgeries, patients with tracheostomy or rib fractures.

\section{2- Tools:}

\section{For assessment:}

Laboratory GEM premier 3000: GEM premier 3000 manufactured by (German Instrumentation Laboratory Company). The GEM Premier 3000 system simplifies and standardizes whole blood testing while delivering rapid, quality results in the laboratory or at the point of care [13]. It was used to measure $\mathrm{ABGs}\left(\mathrm{pH}, \mathrm{PaO} 2, \mathrm{SaO}_{2}, \mathrm{PaCO}_{2}\right.$ and $\mathrm{HCO}_{3}$ ).

\section{For treatment:}

1-Ambu Bag: A self inflating double ended silicone bag $(1800 \mathrm{ml} \mathrm{K} \&$ L Kyoling-India) made of plastic materials that re-expand after being manually collapsed was used to deliver the $\mathrm{MH}$ breaths [14]

2- Mechanical vibrator: Thrive (220-240 volt/50$60 \mathrm{HZ} / 18$ watt) made in Japan was used to deliver mechanical oscillatory movement to the patient's chest wall to loosen and mobilize the secretions [15]

3- Suctioning device: Portable Suction Unit (NEW ASKIR 30, BioMatrix, Italy) suitable for nasal, oral and endotracheal aspiration of bodily fluids (mucus or catarrh) from adults [16]

\section{3- Procedures:}

The whole procedure was explained for every patient's relatives. Relatives signed an informed consent before the beginning of the study to insure complete satisfaction. The study had an approval from the Ethical Committee of the Faculty of Physical Therapy, Cairo University (No:P.T.REC/ 012/002442).

All patients' relatives were given a full explanation of the protocol of the study and a consent form was signed before participating in the study. All patients recruited to the study have been ventilated by Servo Ventilator-900C or Servo ventilator-300C ventilation systems. 
A-Assessment: The operational self check system (designed to ensure optimal function) of the ventilator have been performed before use for each patient. Baseline data including age, gender, admission diagnosis, ventilatory mode, type of intubation, radiological features, and clinical parameters, Glasgow Coma Score (GCS) of all the patients prior to the chest physiotherapy was noted.

\section{Arterial Blood Gases (ABG) analysis:}

The assessment was carried out at the Laboratory of Biochemistry Department in Cairo University Hospitals using GEM premier 3000 device. Arterial blood samples $(3 \mathrm{ml})$ from the radial artery were collected with a thin needle from each patient before and after the study.

All outcome measures will be evaluated $5 \mathrm{~min}$ before the physiotherapy session and $15 \mathrm{~min}$ after ending the physiotherapeutic intervention [17].

$B$ - Treatment procedure: Chest physiotherapy protocol administrated in form of (manual hyperinflation, mechanical vibration, percussion, upper and lower limbs exercise and ending position).

1-Manual hyperinflation (MH): Patients received $\mathrm{MH}$ to a peak airway pressure of $20 \mathrm{cms}$ of $\mathrm{H} 2 \mathrm{O}$ by the use of resuscitator bag. The resuscitator was slowly compressed with both hands and an inspiratory breath was maintained for 3 to 5 seconds at end of pressing half of the resuscitator, and then completely pressing the resuscitator. Expiration was passive and unobstructed to facilitate expiratory flow with no positive end expiratory pressure applied. The MH procedure was carried out at rate of 8 to 13 breaths/min for a period of 5 minutes [18].

2- Mechanical vibration: The patient was positioned in supine and then positioned right and left side lying in the bed.

Thrive mechanical vibrator was placed anteriorly and laterally on the patient's chest. The therapist applied vibration in the expiratory phase of breathing. The technique was repeated thrice in each of the three zones i.e. upper zone, mid zone and lower zone of the chest for a total period of 5 minutes [19].

3-Percussion: It was done manually (using cupped hands) by clapping the chest wall over of the lungs at the same positions of the vibration for 5 minutes [19].
4- Limb exercises: In the form of passive movement for the 4 limbs ( 2 sets for each limb and each set 10 repetitions) for 15 minutes. Limb exercises were performed according to patient's status [19].

5- Ending position: At the end of the treatment session, the head was elevated to about 30-45 degrees (as measured by goniometer) and maintained for minimum of 30 minutes for improving ventilation in all patients [7].

6- Suctioning: The catheter was inserted fully up to the carina and then withdrawn for one $\mathrm{cm}$ prior to the application of negative pressure. The suctioning session involved instillation of one $\mathrm{ml}$ of normal saline in the tracheal tube, followed by suctioning once every minute for four minutes.

During suctioning, the secretions from the lower respiratory tract were collected in a sterile container.

IV- Statistical design and data analysis:

- Statistical analyses were performed using SPSS software (version 20).

- Descriptive statistics (means and standard deviations).

- Paired $t$-test for comparison between pre and post-treatment mean values.

-All statistically significant differences were determined with confidence interval of $95 \%$ and significance will be set at $p \leq 0.05$.

\section{Results}

The purpose of this study was to analyze the acute effect of chest physical therapy on arterial blood gases of mechanically ventilated patients. The patients were assigned into one study group which included sixty mechanically ventilated patients from ICUs of Cairo University Hospitals.

Data obtained pre and post-treatment regarding Arterial Blood Gases (ABG) were statistically analyzed and compared.

Analysis of results:

\section{General characteristics of the subjects:}

The mean values of age and GCS were 51.14 \pm 5.79 year and $7.02 \pm 1.55$ respectively. The sex distribution revealed that there were 27 females with reported percentage of $45 \%$ and 33 males with reported percentage of $55 \%$.

1- $P H$ : The mean values of $\mathrm{PH}$ pre and post study were $7.32 \pm 0.18$ and $7.34 \pm 0.15$ respectively. 
There was no significant difference ( $p=0.36)$. The percentage of increase was $0.002 \%$ (Table 1).

2- $\mathrm{PaO}_{2}$ : The mean values of $\mathrm{PaO}_{2}$ pre and post study were $73.76 \pm 10.1$ and $77.51 \pm 10.5$ respectively. There was a significant increase ( $p$ $<0.001)$. The percentage of increase was $5 \%$ (Table 1).

3- $\mathrm{SaO}_{2}$ : The mean values of $\mathrm{SaO}_{2}$ pre and post study were $86.30 \pm 6.8$ and $90.51 \pm 6.28$ respectively. There was a significant increase $(p$
$<0.001)$. The percentage of increase was $7.9 \%$ (Table 1).

4- $\mathrm{PaCO} 2$ : The mean values of $\mathrm{PaCO} 2$ pre and post study were $50.45 \pm 11.1$ and $46.73 \pm 9.59$ respectively. There was a significant decrease $(p<0.001)$. The percentage of decrease was $7.9 \%$ (Table 1).

5- $\mathrm{HCO} 3$ : The mean values of $\mathrm{HCO}_{3}$ pre and post study were $50.45 \pm 11.1$ and $46.73 \pm 9.59$ respectively. There was no significant difference $(p=0.15)$. The percentage of increase was $2.06 \%$ (Table 1).

Table (1): General characteristics of patients in all groups.

\begin{tabular}{llllll}
\hline Variables & \multicolumn{1}{c}{ Pre } & \multicolumn{1}{c}{ Post } & \% of change & $t$-value & $p$-value \\
\hline $\mathrm{PH}(\mathrm{H}+)$ & $7.32 \pm 0.18$ & $7.34 \pm 0.15$ & 0.002 & -0.910 & 0.36 \\
$\mathrm{PaO}_{2}(\mathrm{mmHg})$ & $73.76 \pm 10.1$ & $77.51 \pm 10.5$ & 5 & -4.2 & $<0.001^{*}$ \\
$\mathrm{SaO}_{2}(\%)$ & $86.30 \pm 6.8$ & $90.51 \pm 6.28$ & 4.8 & -6.82 & $<0.001^{*}$ \\
$\mathrm{PaCO} 2(\mathrm{mmHg})$ & $50.45 \pm 11.1$ & $46.73 \pm 9.59$ & 7.9 & 5.28 & $<0.001^{*}$ \\
$\mathrm{HCO} 3(\mathrm{mEq} / \mathrm{L})$ & $25.68 \pm 3.95$ & $26.21 \pm 5$ & 2.06 & -1.44 & 0.15 \\
\hline $\mathrm{Data}$ are expressed in means $\pm \mathrm{SD}$. & \multicolumn{5}{c}{ PaCO2: Partial pressure of arterial carbon dioxide. } \\
$\mathrm{PH} \quad$ : Potential Hydrogen. & $p>0.05$ : Non-significant. \\
$\mathrm{PaO} 2:$ Partial pressure of arterial oxygen. & $p \leq 0.05$ : Significant. \\
$\mathrm{SaO} 2$ : Oxygen saturation. &
\end{tabular}

\section{Discussion}

Approximately one third of all patients who enter the ICU require mechanical ventilation. These patients have an increased risk of developing chest infection and atelectasis, besides an increased risk of sputum retentions leading to ventilation weaning more difficult and resulting in excess morbidity and mortality [20].

The present study was conducted to analyze and investigate the acute effect of chest physical therapy on arterial blood gases of mechanically ventilated patients. Sixty mechanically ventilated patients from both sexes were assigned into one study group who received a chest physiotherapy protocol in form of (manual hyperinflation, vibration, percussion, suctioning, upper and lower limbs exercise and ending position). All the patients were evaluated before and after the study measuring ABGs (pH, $\mathrm{PaO}_{2}, \mathrm{SaO}_{2}, \mathrm{PaCO}_{2}$ and $\left.\mathrm{HCO} 3\right)$.

Arterial Blood Gases (ABG) were assessed pre and post study. The results of the study proved that a marked improvement in arterial blood gas exchange as compared to base line reflected by a highly significant statistical increase in $\mathrm{PaO}_{2}$ and $\mathrm{SaO}_{2}(p<0.001)$ and a significant decrease in $\mathrm{PaCO} 2$ $(p<0.001)$ while there were no significant changes regarding $\mathrm{pH}$ and $\mathrm{HCO}_{3}(p=0.36$ and 0.15 respectively).
The improvement of ABG could be explained by decreasing resistance and obstruction caused by secretions and bulges that increases airway pressure \& decrease compliance. Chest physiotherapy helps to clears the accumulation of secretions and improve lung mechanics [21].

Wang, [22] stated that when airways are clear from secretions, the volume of air moving in his lungs increases, the alveoli open, promoting good oxygen, carbon dioxide exchange resulting improvement in $\mathrm{PaO}_{2}$ and $\mathrm{SaO}_{2}$, fluid electrolytes \& acid base balance with the body maintains health and function in all body system. Hess and Bigatello, [23] reported that chest physiotherapy causes an intentional transient increase in intrapulmonary pressure to promote reopening of unstable or collapsed alveoli and thereby improve gas exchange.

Zaman, [24] performed two studies into the efficiency of chest physiotherapy and found that chest physiotherapy is useful in preventing pulmonary complications and described the aim of chest physiotherapy being to 'minimize pulmonary secretion retention, to maximize oxygenation and to re-expand atelectatic lung segments and concluded that chest physiotherapy is clearly effective in intubated patients with acute lobar collapse.

The improvement may be also attributed to that chest physiotherapy procedures help to reinflate 
the collapsed lobe of a lung, positioning combined with chest percussion, as well as lung hyperinflation plus suction, are the best ways to quickly solve lung lobe atelectasis [9].

Seckel and Remel, [25] stated that percussion and vibration methods apply an external force to the chest wall to loosen the mucus facilitates airway mobilization and clearance. Moreover, both increase expiratory flow and subsequent pulmonary secretion clearance. During vibration, the chest behaves as highly linear system. Changes in the intra-pleural pressure occurring during vibration appear to be the sum of changes in the pressure due to lung recoil and the compressive and oscillatory components of the technique.

Above so, passive movements improve ventilation, central and peripheral perfusion, circulation, muscle metabolism and alertness and countermeasures for venous stasis and deep vein thrombosis [26]. Positioning can be also used to increase gravitational stress and associated fluid shifts that increases lung volumes and gas exchange, stimulates autonomic activity, and can reduce cardiac stress from compression [27].

The results of the present study agreed with the results of Hedenstierna, [28] who conducted a study to determine the effect of chest physical therapy on mechanically ventilated patients and found highly statistical significant difference in study group compared to control group with $(p<0.01)$. After 30 minutes of chest physical therapy, Recruitment maneuvers improved oxygen saturation and $\mathrm{FiO}_{2}$ from baseline measurements.

Zhong et al., [29] conducted a study to identify the effect of early chest physiotherapy (positioning, percussion, vibration and suction) on blood gas and circulatory function in 15 old ventilated patients after thoracotomy and found that $\mathrm{PaO}_{2}, \mathrm{SaO}_{2}$ were significantly increased and $\mathrm{PaCO} 2$ were decreased at 30 minutes after treatment.

The current study agreed with Hussey et al., [30] who conducted a study on 45 mechanically ventilated pediatric subjects to determine Oxygenation index $\left(\mathrm{PaO}_{2} / \mathrm{FiO}_{2}\right)$ and $\mathrm{PaCO} 2$ changes after 30 minutes of different mode of chest physiotherapy (percussion, vibration and bagging). Hussey et al., found that there was significant improvement in $\mathrm{PaO}_{2} / \mathrm{FiO}_{2}$ following percussion and suctioning $(p=0.008) . \mathrm{PaCO} 2$ improved towards normal $(p=$ $0.007)$.

The results of the present study comes in line with the findings of Barker and Adams, [31] who conducted a study on 60 mechanically ventilated patients to identify the effects of chest physiotherapy and recruitment maneuvers on lung mechanics and pulmonary complications and found a highly significant statistical increase in $\mathrm{PaO}_{2}$ and $\mathrm{SaO}_{2}$ and a significant decrease in $\mathrm{PaCO}_{2}(p<0.001)$ while there were no significant changes regarding $\mathrm{pH}$ and $\mathrm{HCO}_{3}$ after 30 minutes of chest physical therapy interventions.

The results of the present study contradicted with the finding of Paratz et al., [32] who examined the effect of manual hyperinflation on hemodynamics, gas exchange, and respiratory mechanics in ventilated patients and demonstrated that there was a decrease in $\mathrm{PaO}_{2}$ with no change in $\mathrm{PCO} 2$ after manual hyperinflation in patient with acute intrapulmonary lung injuries. This contradiction may be as a result of that the candidates were having acute intrapulmonary lung injuries who were excluded from this study, besides applying manual hyperinflation only.

Also, Lagerkvist et al., [33] found no changes in $\mathrm{PaCO} 2$ and $\mathrm{PaO}_{2}$ in patients with cystic fibrosis on mechanical ventilator after chest physical therapy. They suggested that their results could be due to the relatively high baseline oxygen-saturation values of the patients in their study. In the present study, also, patients with a normal baseline $\mathrm{PaCO}_{2}$ and $\mathrm{PaO}_{2}$

\section{Conclusion:}

Based on the findings of this study, chest physiotherapy protocol in form of (manual hyperinflation, vibration, percussion, suctioning, upper and lower limbs exercise and ending position) is an effective method for improving arterial blood gases of mechanical ventilated patients acutely.

\section{References}

1- ÅKERMAN E.: Intensive Care Unit diaries: A critical appraisal. Intensive and Critical Care Nursing, 47 (5): pp. 5-6, 2018.

2- ZAMPIERI F. and MAZZA B.: Mechanical Ventilation in Sepsis. SHOCK, 47 (8): pp. 41-6, 2017.

3- KACMAREK R.: The Mechanical Ventilator: Past, Present, and Future. Respiratory Care, 56 (8): pp. 1170-80, 2011.

4- CHARLES M.: Incidence and risk factors of ventilator associated pneumonia in a tertiary care hospital. Australasian Medical Journal, 6 (4): pp. 178-82, 2013.

5- GUPTA A., JAIN H., REHMAN A. and CHOUBEY P.: Comparison of Arterial and Venous Blood Gas Measurements in Non-Respiratory Diseases Patients Admitted in Intensive Care Unit (ICU). Scholars Journal of Applied Medical Sciences, 4 (6): pp. 1913-8, 2016. 
6- ZEPPOS L., PATMAN S., BERNEY S., ADSETT J., BRIDSON J. and PARATZ J.: Physiotherapy intervention in intensive care is safe: An observational study. Australian Journal of Physiotherapy, 53 (4): pp. 279-83, 2007.

7- PATTANSHETTY R. and GAUDE G. Effect of multimodality chest physiotherapy in prevention of ventilatorassociated pneumonia: A randomized clinical trial. Indian Journal of Critical Care Medicine, 14 (2): pp. 70-6, 2010.

8- VOLPE M., NAVES J., RIBEIRO G., RUAS G. and TUCCI M.: Effects of manual hyperinflation, clinical practice versus expert recommendation, on displacement of mucus simulant: A laboratory study. PLOS ONE, 13 (2): p. e191787, 2018.

9- NOWOBILSKI R., WLOCH T., PLASZEWSKI M. and SZCZEKLIK A.: Efficacy of physical therapy methods in airway clearance in patients with chronic obstructive pulmonary disease. A critical review. Polish Archives of Internal Medicine, 120 (11): pp. 468-78, 2010.

10-MEZIDI M. and GUÉRIN C.: Effects of patient positioning on respiratory mechanics in mechanically ventilated ICU patients. Annals of Translational Medicine, 6 (19): pp. 384,2018 .

11-ZHANG G., ZHANG K., CUI W., HONG Y. and ZHANG Z.: The effect of early mobilization for critical ill patients requiring mechanical ventilation: A systematic review and meta-analysis. Journal of Emergency and Critical Care Medicine, 2 (8): pp. 9, 2018.

12- YUE M., MA Z., LEI M., CUI C. and JIN Y.: Early mobilization for mechanically ventilated patients in the Intensive Care Unit: A systematic review and metaanalysis. Frontiers of Nursing, 5 (4): pp. 301-10, 2018.

13- VUKELIC N., PAPIC FUTAC D. and TOPIC E.: Analytical properties of the GEM premier 3000 analyzer evaluated. Biochemia Medica, 7 (21): pp. 231-41, 2007.

14- AHMED F., SHAFEEQ A., MOIZ J. and GEELANI M.: Manual hyperinflation-PEEP to recruit and rapid release for clearance of airway secretions. Heart \& Lung, 40 (3): pp. 271-2, 2011.

15- O'RIORDAN T., WEINSTEIN M., ABRAHAM W. and FORTEZA R.: Elevated Tissue Kallikrein Activity in Airway Secretions from Patients with Tracheobronchitis Associated with Prolonged Mechanical Ventilation. Lung, 181 (5): pp. 237-44, 2003.

16- ARNSTEIN F. and SMITH G.: Portable suction devices. Anaesthesia, 49 (3): pp. 260-1, 2007.

17-DOSSANTOS R., DONADIO M., Da SALVIA G., BLATTNER C.,MELO D., NUNES F., DIAS F., SQUIZANI E., PEDRAZZA L., GADEGAST I. and De OLIVEIRS J.: Immediate effects of chest physiotherapy on hemodynamic, metaolic, and oxidative stress parameters in subjects with septic shock. Respiratory care, 59 (9): pp. 1398-403, 2014.

18- PATTANSHETTY R. and GAUDE G.: Effect of multimodality chest physiotherapy on the rate of recovery and prevention of complications in patients with mechanical ventilation: A prospective study in medical and surgical intensive care units. Indian Journal of Medical Sciences, 65 (5): p. 175, 2011.
19- MEAWAD M., ABD EL AZIZ A., OBAYA H. and MOHAMED S.: Effect of Chest Physical Therapy Modalities on Oxygen Saturation and Partial Pressure of Arterial Oxygen in Mechanically Ventilated Patients. The Egyptian Journal of Hospital Medicine, 72 (8): pp. 5004-8, 2018.

20- BAKOWITZ M., BRUNS B. and McCUNN M.: Acute lung injury and the acute respiratory distress syndrome in the injured patient. Scandinavian Journal of Trauma, Resuscitation and Emergency Medicine, 20 (1): p. 54, 2012.

21- MEINDERS A., VAN DER HOEVEN J. and MEINDERS A.: The Outcome of Prolonged Mechanical Ventilation in Elderly Patients: Are the Efforts Worthwhile? Age and Ageing, 25 (5): pp. 353-6, 2004.

22- WANG T.: Basic and clinical research progress in acute lung injury/acute respiratory distress syndrome. Infection International, 7 (2): pp. 38-43, 2018.

23- HESS D. and BIGATELLO L.: The chest wall in acute lung injury/acute respiratory distress syndrome. Current Opinion in Critical Care, 14 (1): pp. 94-102, 2008.

24- ZAMAN B.: Comparative Study on the Immediate Effects of Deep Breathing Exercises with PEP Device Verses Incentive Spirometry with EPAP on Preventing Pulmonary Complications Following CABG. International Journal of Physiotherapy, 3 (1): pp. 132-6, 2016.

25- SECKEL M. and REMEL B.: Evidence-Based Practice: Percussion and Vibration Therapy. Critical Care Nurse, 37 (3): pp. 82-3, 2017.

26- GOSSELINK R., BOTT J., JOHNSON M., DEAN E., NAVA S., NORRENBERG M., SCHÖNHOFER B., STILLER K., VAN DE LEUR, H. and VINCENT J.: Physiotherapy for adult patients with critical illness: Recommendations of the European Respiratory Society and European Society of Intensive Care Medicine Task Force on Physiotherapy for Critically Ill Patients. Intensive Care Medicine, 34 (7): pp. 1188-99, 2008.

27- CHANG A., BOOTS R., HODGES P. and PARATZ J.: Standing with assistance of a tilt table in intensive care: A survey of Australian physiotherapy practice. Australian Journal of Physiotherapy, 50 (1): pp. 51-4, 2004.

28- HEDENSTIERNA G.: Small Tidal Volumes, Positive End-expiratory Pressure, and Lung Recruitment Maneuvers during Anesthesia. Anesthesiology, 123 (3): pp. 5013,2015 .

29- ZHONG X., LIN H. and MA J.: Early Postoperative Chest Physical Therapy Effects on Respiratory Function in Patients With Lung Transplantation. Chest, 149 (4): p. A489, 2016

30- HUSSEY J., GROFF A. and REDMER J.: Chest physiotherapy following pediatric cardiac surgery. The influence of mode of treatment on oxygen saturation and hemodynamic stability. Physiotherapy Theory and Practice, 12 (1): pp. 77-85, 1996.

31- BARKER M. and ADAMS S.: An evaluation of a single chest physiotherapy treatment on mechanically ventilated patients with acute lung injury. Physiotherapy Research International, 7 (3): pp. 157-69, 2002. 
32- PARATZ J., LIPMAN J. and McAULIFFE M.: Effect of Manual Hyperinflation on Hemodynamics, Gas Exchange, and Respiratory Mechanics in Ventilated Patients. Journal of Intensive Care Medicine, 17 (6): pp. 317-24, 2002.
33- LAGERKVIST A., STEN G., REDFORS S. and HOLMGREN D.: Repeated blood gas monitoring in healthy children and adolescents by the transcutaneous route. Pediatric Pulmonology, 35 (4): pp. 274-9, 2003.

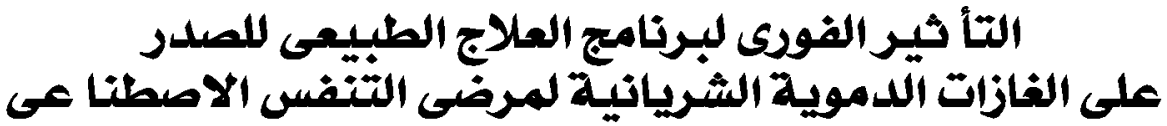

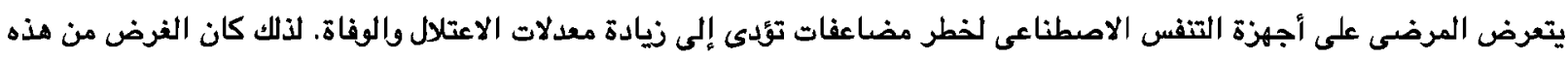

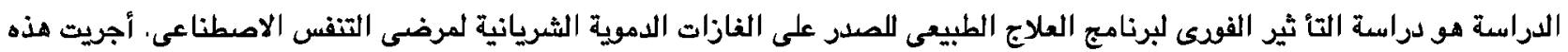

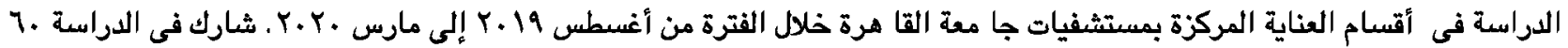

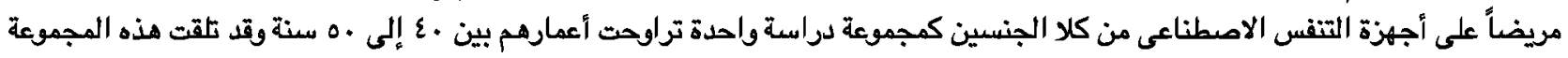

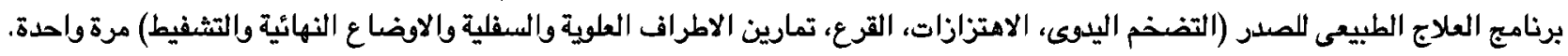

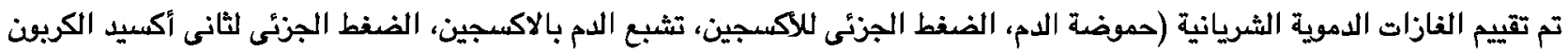

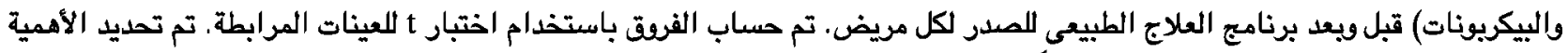

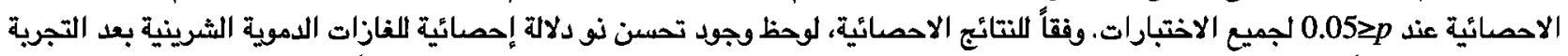

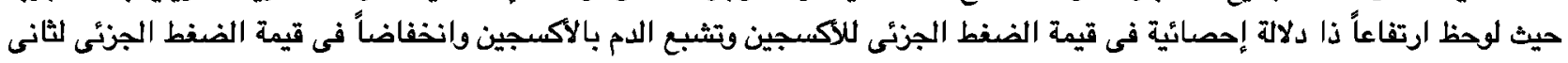

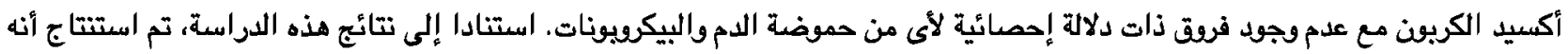

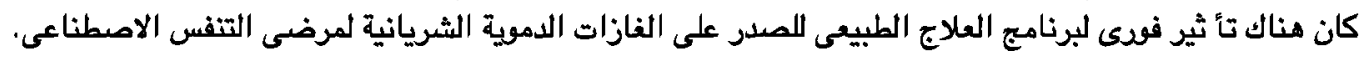

